Document downloaded from:

http://hdl.handle.net/10251/51244

This paper must be cited as:

Sánchez Tovar, R.; Fernández Domene, RM.; García-García, D.; García Antón, J. (2015). Enhancement of photoelectrochemical activity for water splitting by controlling hydrodynamic conditions on titanium anodization. Journal of Power Sources. 286:224-231. doi:10.1016/j.jpowsour.2015.03.174.

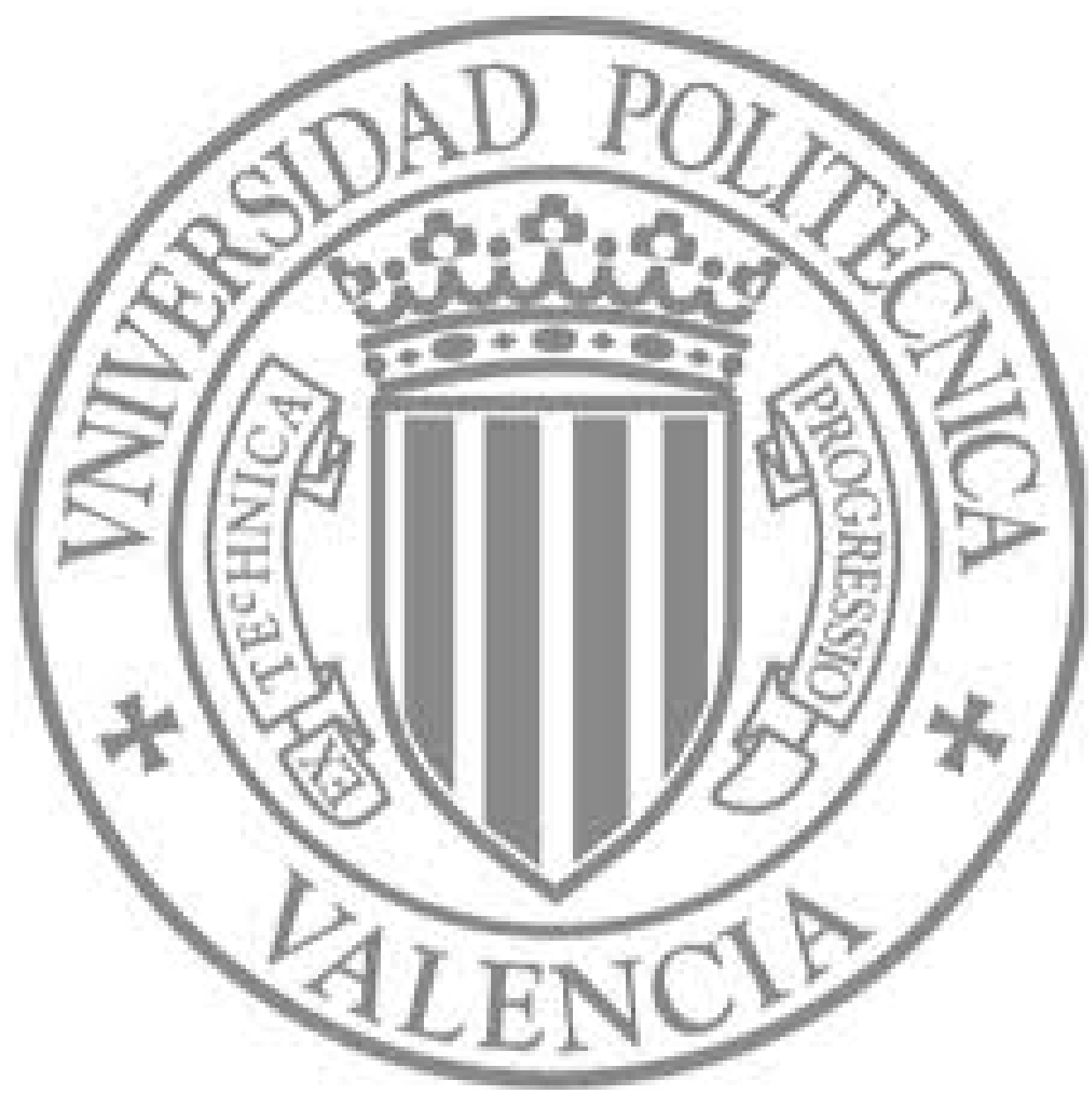

The final publication is available at

http://dx.doi.org/10.1016/j.jpowsour.2015.03.174

Copyright Elsevier 


\title{
ENHANCEMENT OF PHOTOELECTROCHEMICAL ACTIVITY FOR WATER SPLITTING BY CONTROLLING HYDRODYNAMIC CONDITIONS ON TI ANODIZATION
}

\author{
Sánchez-Tovar, R.; Fernández-Domene, R.M., García-García, D.M., García- \\ Antón, J. * \\ Ingeniería Electroquímica y Corrosión (IEC). Departamento de Ingeniería Química y \\ Nuclear. ETSI Industriales. Universitat Politècnica de València. Camino de Vera s/n, \\ 46022 Valencia, Spain.
}

Tel. 34-96-387 76 32, Fax. 34-96-387 76 39, e-mail: jgarciaa@iqn.upv.es

This work studies the electrochemical and photoelectrochemical properties of a new type of $\mathrm{TiO}_{2}$ nanostructure (nanosponge) obtained by means of anodization in a glycerol/water $/ \mathrm{NH}_{4} \mathrm{~F}$ electrolyte under controlled hydrodynamic conditions. For this purpose different techniques such as Scanning Electronic Microscopy (SEM), Raman Spectroscopy, Electrochemical Impedance Spectroscopy (EIS) measurements, MottSchottky (M-S) analysis and photoelectrochemical water splitting tests under standard AM 1.5 conditions have been carried out. Obtained results have shown that electronhole separation is facilitated in the $\mathrm{TiO}_{2}$ nanosponge if compared with highly ordered $\mathrm{TiO}_{2}$ nanotube arrays. As a result, nanosponges enhance the photoelectrochemical activity for water splitting.

Keywords: $\mathrm{TiO}_{2}$ nanostructures, anodization, hydrodynamic conditions, water splitting, Electrochemical Impedance Spectroscopy, Mott-Schottky analysis. 


\section{INTRODUCTION}

Titanium dioxide $\left(\mathrm{TiO}_{2}\right)$ is widely used as a pigment, as a catalyst support and as a photocatalyst, among others 1 . This last application has attracted a great scientific and technological interest over the last years [1-38] due to the exclusive set of properties of $\mathrm{TiO}_{2}$, such as a high chemical stability, resistance to photocorrosion and favourable band-edge position relative to the redox potentials for the decomposition of water, allowing for effective direct water splitting using light.

$\mathrm{TiO}_{2}$ is habitually used in form of nanostructures, such as nanoparticles [24, 30, 37], nanorods/nanowires $[20,26,37]$ or nanotubes $[1,6-9,13-15,17-19,22-36,38]$, to obtain high specific surfaces areas and, thus, to increase the photocatalytic activity. In the last years, $\mathrm{TiO}_{2}$ nanotubes have gained increasing attention since they have several advantages with respect to other nanostructures due to their perfectly defined geometry (highly ordered nanotube arrays and a very precise control of their dimensions using the process of anodization for their synthesis) [1]. Furthermore, as the oxide nanotubes formed by anodization are grown directly on the metal substrate (back contact), they can be used directly as photoanodes, thus avoiding compaction or sintering of $\mathrm{TiO}_{2}$ nanoparticles on the metallic substrate.

In recent publications, the influence of hydrodynamic conditions on the anodization process has been evaluated [31], and it has been observed that under flux conditions the geometry of the formed nanostructures is different from that obtained under stagnant conditions, i.e., nanotubes. This new nanostructure, called nanosponge, provides better performance than tube morphologies, for example, for the water splitting process [31]. 
In the present work, $\mathrm{TiO}_{2}$ nanotubes and nanosponges have been obtained by anodization in a glicerol/water/ $\mathrm{NH}_{4} \mathrm{~F}$ mixture using different hydrodynamic conditions. The morphology and electronic properties of both nanostructures have been studied through different techniques, such as Scanning Electronic Microscopy (SEM), Raman Spectroscopy, Electrochemical Impedance Spectroscopy (EIS) measurements and MottSchottky (M-S) analysis. These properties have been correlated to the performance of both nanostructures as photocatalysts for water splitting.

\section{MATERIALS AND METHODS}

Anodization under hydrodynamic conditions was performed in a 2-electrode electrochemical cell with a rotating electrode configuration. The anode was a Teflon coated titanium rod ( $8 \mathrm{~mm}$ diameter, $99.3 \%$ purity) in a rotating electrode setup. For all experiments, $0.5 \mathrm{~cm}^{2}$ of the sample was exposed to the electrolyte. Prior to the anodization process, the titanium rod surface was abraded with 500 to 4000 silicon carbide $(\mathrm{SiC})$ papers, in order to obtain a mirror finish. After this, the sample was sonicated in ethanol for $2 \mathrm{~min}$ and dried in a $\mathrm{N}_{2}$ stream. For anodization a voltage source was used, where the titanium rod served as working electrode and a platinum mesh acted as counter electrode. The electrolyte for these experiments was a mixture of glycerol/water/ammonium fluorine at a concentration of $0.27 \mathrm{M} \mathrm{NH}_{4} \mathrm{~F}$ in glycerol/water (60:40 vol.\%). Different rotation speeds were used: 0, 654, 1307, 1961 and $2614 \mathrm{rpm}$ corresponding to Reynolds numbers (Re) of 0, 100, 200, 300 and 400. The Reynolds numbers $(\mathrm{Re})$ were calculated as follows:

$$
\operatorname{Re}=\frac{\omega \cdot r^{2} \cdot \rho}{\mu}
$$


where $\omega$ is the rotation speed expressed in $\operatorname{rad~s}^{-1}, \mathrm{r}$ is the radius of the working electrode in $\mathrm{cm}$ and $\rho$ and $\mu$ are the density in $\mathrm{g} \mathrm{cm}^{-3}$ and dynamic viscosity in $\mathrm{g} \mathrm{cm}^{-1} \mathrm{~s}^{-1}$ of the solution, respectively [39].

The specimens were anodized at $30 \mathrm{~V}$ by increasing the potential from zero to the desired value at a rate of $200 \mathrm{mV} \mathrm{s}^{-1}$, followed by keeping the end potential for 3 hours. To compare the electrochemical and photoelectrochemical behavior of $\mathrm{TiO}_{2}$ nanostructures with that of a compact $\mathrm{TiO}_{2}$ layer, this layer was obtained anodizing the titanium rod in the same electrochemical cell, i.e., using platinum as counter electrode in $1 \mathrm{M} \mathrm{H}_{2} \mathrm{SO}_{4}$ at $30 \mathrm{~V}$ for 20 min under stagnant conditions.

After each test, a field-emission scanning electron microscope (FE-SEM) was used for morphological characterization of the obtained samples. For electrochemical (EIS and M-S measurements) and photoelectrochemical water splitting measurements, the asformed $\mathrm{TiO}_{2}$ layers were annealed in a furnace at $450{ }^{\circ} \mathrm{C}$ (heating at $30^{\circ} \mathrm{C} \mathrm{s}^{-1}$ ) in air for $1 \mathrm{~h}$. The materials were also examined by Raman spectroscopy ("Witec Raman microscope") after the heat treatment, in order to evaluate their crystalline structure. For these measurements, a $632 \mathrm{~nm}$ neon laser with $420 \mu \mathrm{W}$ was used.

For the electrochemical and photoelectrochemical water splitting tests, a three-electrode configuration was used. The area of the $\mathrm{TiO}_{2}$ nanostructures (working electrode) exposed to the test solution was $0.13 \mathrm{~cm}^{2}$. A saturated $\mathrm{Ag} / \mathrm{AgCl}(3 \mathrm{M} \mathrm{KCl})$ electrode was the reference electrode, and a platinum tip was the counter electrode. 
The electrochemical measurements were conducted in a $0.1 \mathrm{Na}_{2} \mathrm{SO}_{4}$ solution using an Autolab PGSTAT302N potentiostat under dark conditions (without irradiation). EIS experiments were conducted at the open circuit potential (OCP) over a frequency range from $100 \mathrm{kHz}$ to $10 \mathrm{mHz}$ with a $10 \mathrm{mV}$ (peak to peak) signal amplitude. Mott-Schottky plots were subsequently obtained by sweeping the potential from the OCP in the negative direction at $10 \mathrm{mV} \mathrm{s}^{-1}$ with an amplitude signal of $10 \mathrm{mV}$ at a frequency value of $10 \mathrm{kHz}$.

The photoelectrochemical experiments were carried out under simulated sunlight condition AM $1.5\left(100 \mathrm{~mW} \mathrm{~cm}^{2}\right)$ in a $1 \mathrm{M} \mathrm{KOH}$ solution. Photocurrent vs. voltage characteristics were recorded by scanning the potential from $-0.8 \mathrm{~V}$ to $+0.5 \mathrm{~V}$ with a scan rate of $2 \mathrm{mV} \mathrm{s}^{-1}$. Photocurrent transients as a function of the applied potential were recorded by chopped light irradiation (60 s in the dark and $20 \mathrm{~s}$ in the light). Samples were left at $+0.5 \mathrm{~V}$ in the light for one hour, in order to evaluate their stability to the photocorrosion attack.

\section{RESULTS AND DISCUSSION}

Figure 1 shows the scanning electron microscope (SEM) images of the $\mathrm{TiO}_{2}$ nanostructures obtained under stagnant conditions $(\operatorname{Re}=0$, Figure 1a) and under hydrodynamic conditions $(\operatorname{Re}=300$, Figure 1b). Under stagnant conditions, organized nanotubes of $1.3 \mu \mathrm{m}$ in length with pore diameters of 130 and $224 \mathrm{~nm}$ in inner and outer diameter were formed. On the other hand, the hydrodynamic conditions changed the morphology of the formed nanostructures from nanotubes to nanosponges, i.e., a connected and highly porous $\mathrm{TiO}_{2}$ structure. Figure 2 shows that the thickness of the 
nanosponges is enhanced in comparison to that obtained for the nanotubes. Additionally, an increase in the rotation rate made nanosponges thicker (from 2 to nearly $3.5 \mu \mathrm{m})$. The formed nanosponges have pore openings of roughly $50 \mathrm{~nm}$.

\subsection{Raman Spectra}

As an example, Figure 3 shows the spectra of as-prepared and annealed $\mathrm{TiO}_{2}$ nanostructures for $\operatorname{Re}=0$ and $\operatorname{Re}=300$. Raman peaks originate from the molecular bond and provide useful information such as crystal structure, phase purity and crystallinity. The as-prepared $\mathrm{TiO}_{2}$ does not clearly show defined peaks and only a single baseline is present. According to other studies [40,41], there are six active RS bands for anatase, i.e.: $144 \mathrm{~cm}^{-1}\left(\mathrm{E}_{\mathrm{g}}\right), 197 \mathrm{~cm}^{-1}\left(\mathrm{E}_{\mathrm{g}}\right), 399 \mathrm{~cm}^{-1}\left(\mathrm{~B}_{1 \mathrm{~g}}\right), 513 \mathrm{~cm}^{-1}\left(\mathrm{~A}_{1 \mathrm{~g}}\right), 519$ $\left(B_{1 \mathrm{~g}}\right)$ and $639\left(\mathrm{E}_{\mathrm{g}}\right)$. For species after annealing, the specific bands were recorded in the range of $149 \mathrm{~cm}^{-1}, 197 \mathrm{~cm}^{-1}, 398 \mathrm{~cm}^{-1}, 516 \mathrm{~cm}^{-1}, 637 \mathrm{~cm}^{-1}$. These results show that the heat treatment improves the crystallinity of $\mathrm{TiO}_{2}$ and the peaks obtained correspond to $\mathrm{TiO}_{2}$ anatase phase.

\subsection{EIS measurements}

Figure 4 shows the experimental Nyquist and Bode plots for the compact $\mathrm{TiO}_{2}$ film and $\mathrm{TiO}_{2}$ nanostructures formed at different $\mathrm{Re}$, measured in a $0.1 \mathrm{M} \mathrm{Na} 2 \mathrm{SO}_{4}$ solution at open circuit potential under dark conditions and at $25^{\circ} \mathrm{C}$. In the case of the compact $\mathrm{TiO}_{2}$ film, Nyquist and Bode plots exhibit the typical passive state behavior characterized by a semicircular shape and high impedance values in the Nyquist and Bode-module plots (Figures 4(a) and 4(d)), as well as phase angles close to 90 degrees (Figure 4(c)), suggesting the formation of a highly stable $\mathrm{TiO}_{2}$ passive film on the $\mathrm{Ti}$ 
electrode [42]. The presence of a shoulder in the Bode-phase plot at intermediate frequencies (Figure 4(c)) suggests the existence of two time constants.

In the case of the $\mathrm{TiO}_{2}$ nanostructures (nanotubes and nanosponges), the presence of two well-defined time constants can be observed, which could be associated with the nanoporous nature of the $\mathrm{TiO}_{2}$ layer [27]. The shape of the EIS plots is characterized in this case by a distorted small semicircle at high frequencies followed by an unfinished semicircle at low frequencies, with a much higher amplitude (Figures 4(b) and 4(c)). In this case, impedance values are clearly lower than for the compact $\mathrm{TiO}_{2}$ film (Figures 4(a) and 4(d)). It can be observed from the inset in Figure 4(b) that the amplitude of the small semicircle at high frequencies is larger for $\operatorname{Re}=0$ and decreases with increasing Re values. Furthermore, two peaks are perfectly discernible from Bode-phase plots, the peak at low frequencies being always higher than that at high frequencies, regardless of the value of Re.

Experimental EIS data can be represented with an electrical equivalent circuit made up of two RC time constants associated in series (Figure 5). This equivalent circuit has been used in the literature to model the impedance data of compact and nanoporous $\mathrm{TiO}_{2}$ films $[7,8,14,27,34,43]$. Constant phase elements (CPEs) have been used instead of pure capacitors to account for frequency dispersion and non-ideality. CPEs have been converted into pure capacitances, $C$, by using the following equation [44, 45]:

$$
C=\frac{(Q \cdot R)^{1 / \alpha}}{R}
$$


where $Q$ is the impedance of the $\mathrm{CPE}$ and $R$ corresponds to $R_{2}$ when determining capacitance values of the second time constant in Figure 5. To determine $C_{1}$ from $C P E_{1}, R$ has been calculated as follows:

$$
\frac{1}{R}=\frac{1}{R_{S}}+\frac{1}{R_{1}}
$$

The values of the equivalent circuit parameters are shown in Table $\mathbf{1}$, where $R_{S}$ is always the electrolyte resistance. In the case of the compact $\mathrm{TiO}_{2}$ film the time constant at high frequencies $\left(R_{l} C P E_{l}\right)$ is related to the outer layer of the passive film, and the low-frequency behavior is attributed to the inner layer of the film, more compact than the outer one $[42,43]$. In the case of the nanostructured $\mathrm{TiO}_{2}$ layers, and according to the obtained values, the $R_{l} C P E_{1}$ time constant is related to the $\mathrm{TiO}_{2}$ nanoporous structure $[5,14,22]$, whereas the $R_{2} C P E_{2}$ time constant is associated with the charge transfer processes at the bottom of the $\mathrm{TiO}_{2}$ layer $[5,14]$ or with a compact $\mathrm{TiO}_{2}$ underlayer $[7,8,22]$.

The values of $R_{1}$ and $R_{2}$ for the compact $\mathrm{TiO}_{2}$ film are of the order of hundreds of $\mathrm{k} \Omega \mathrm{cm}^{2}$ (Table 1). In the case of the nanostructures, it can be observed that $R_{2}$ values are similar to those obtained for the compact $\mathrm{TiO}_{2}$ film and are significantly higher (two orders of magnitude) than the values associated with the internal resistance of the nanostructures, $R_{1}$. These results imply, first, that in the case of the $\mathrm{TiO}_{2}$ nanostructures $R_{2}$ can be associated with a compact $\mathrm{TiO}_{2}$ underlayer; second, that the nanoporous overlayer $\left(\mathrm{TiO}_{2}\right.$ nanotubes and nanosponges) has a higher surface area and higher density of defects than the compact $\mathrm{TiO}_{2}$ underlayer, leading to a higher conductivity compared to the base oxide $[22,27]$. 
The $\mathrm{CPE}_{1}$ constant, $\alpha_{1}$, takes values of $0.7-0.8$ and is always lower than $\alpha_{2}$, the latter being close to unity in all cases. These results imply a significantly rough morphology of the nanoporous $\mathrm{TiO}_{2}$ overlayer (nanotubes and nanosponges), more conductive and defective than the underlying $\mathrm{TiO}_{2}$ layer whose behavior approximates that of an ideal capacitor $[27,34]$. For the nanoporous structures, $C_{1}$ values are considerably lower than those of $C_{2}$, regardless of the value of Re. Besides, $C_{2}$ values are visibly higher in the case of the nanostructures than for the compact $\mathrm{TiO}_{2}$ film. The high values obtained for $C_{2}$ can be explained by a decrease in the $\mathrm{TiO}_{2}$ underlayer thickness or by an increase in the porosity of this layer as a consequence of a transition from a mostly compact inner layer to a porous layer [7, 27].

Concerning the comparison between the different nanostructures obtained in this work (nanotubes and nanosponges), the resistance of these nanostructures, $R_{l}$, decreases with increasing Re, indicating that the nanosponges formed under hydrodynamic conditions possess higher electrical conductivity than the nanotubes formed under stagnant conditions. No clear tendency of $R_{2}$ values is observed with $R e$, indicating that the electrical properties of the compact $\mathrm{TiO}_{2}$ underlayer are not dependant on the hydrodynamic conditions. Together with the lower values of $\alpha_{1}$ in the case of $\operatorname{Re}>0$, the previous results indicate a higher degree of porosity in the nanosponges formed under hydrodynamic conditions compared with the nanotubes formed with $\operatorname{Re}=0$. The decrease in $C_{1}$ with increasing Re can be explained by a decrease in the density of charge carriers in the nanosponges [35], as it will be verified later with Mott-Schottky analysis. 


\subsection{Mott-Schottky analysis}

Figure 6(a) shows the Mott-Schottky plots at a frequency of $10 \mathrm{kHz}$ for the compact $\mathrm{TiO}_{2}$ film and $\mathrm{TiO}_{2}$ nanostructures formed at different $\mathrm{Re}$, measured in a $0.1 \mathrm{M} \mathrm{Na}_{2} \mathrm{SO}_{4}$ solution at open circuit potential under dark conditions and at $25^{\circ} \mathrm{C}$. These plots have been obtained at a frequency of $10 \mathrm{kHz}$ since at this high value the capacitance dependence on frequency is eliminated $[16,42,46]$. Figure $\mathbf{6}(\mathbf{b})$ is a magnification and only shows the M-S plots for the $\mathrm{TiO}_{2}$ nanostructures. The positive slopes of the M-S plots are characteristics of $n$-type semiconductors, with the dominant defects in $\mathrm{TiO}_{2}$ being oxygen vacancies due to their lower formation energy compared with $\mathrm{Ti}^{3+}$ interstitials [22, 38, 47-51]. It can be observed that capacitance values are notably lower for the compact $\mathrm{TiO}_{2}$ layer (higher values of $C^{-2}$ ), which is consistent with capacitance values obtained above by EIS (Table 1).

The donor density, $N_{D}$, can be determined from the positive slopes of the straight lines in the M-S plots using the Mott-Schottky equation for an $n$-type semiconductor. Although the M-S equations were derived based on a flat electrode, this analysis has been widely used to irregular geometries with porous surfaces such as nanostructures [7, $8,22,25,27,30,37,38,46,52]$. Hence, a qualitative comparison between $N_{D}$ values obtained for different $\mathrm{TiO}_{2}$ layers and nanostructures is valid. The $\mathrm{M}-\mathrm{S}$ expression for $N_{D}$ is $[42,47,53]:$

$$
N_{D}=\frac{2}{\varepsilon \varepsilon_{0} e \sigma}
$$


where $\varepsilon$ is the dielectric constant of the $\mathrm{TiO}_{2}$ layers (a value of 60 has been assumed for the compact $\mathrm{TiO}_{2}$ film [49] and a value of 100 for the $\mathrm{TiO}_{2}$ nanostructures $\left.[34,38]\right), \varepsilon_{0}$ is the vacuum permittivity $\left(8.85 \cdot 10^{-14} \mathrm{~F} / \mathrm{cm}\right), e$ is the electron charge $\left(1.60 \cdot 10^{-19} \mathrm{C}\right)$ and $\sigma$ is the positive slope of each straight line in the M-S plots.

The $N_{D}$ values have been calculated using the geometric area of the electrodes and are presented in Table 2. It can be observed that $N_{D}$ is of the order of $1 \times 10^{18} \mathrm{~cm}^{-3}$ for the compact $\mathrm{TiO}_{2}$ film, while the values for the different nanostructures are considerably higher, of the order of $1-4 \times 10^{19} \mathrm{~cm}^{-3}$. The increase in oxygen vacancies density should improve the $n$-type character of the $\mathrm{TiO}_{2}$ nanostructures and thus enhance the electron transport along the nanostructures [22, 30, 37].

On the other hand, in the case of the $\mathrm{TiO}_{2}$ nanostructures, $N_{D}$ decreases with increasing Re, that is, $N_{D}$ is lower for the nanosponges than for the nanotubes. Although the increase in $N_{D}$ can be a positive effect, since this fact increases the electrical conductivity of $\mathrm{TiO}_{2}$, an increase in $N_{D}$ can also lead to a decrease in the depletion layer thickness, resulting in an increase of recombination losses $[4,16,54]$. If the depletion layer is very thin, photons can penetrate beyond this layer and light will be absorbed in the bulk semiconductor, where the electrical field is absent $[4,16,54,55]$. The lack of an electrical field prevents the photo-excited electron-hole pairs from being effectively separated, thus increasing the probability of recombination $[4,16,27,54]$. Furthermore, oxygen vacancies in $\mathrm{TiO}_{2}$ have been found to act as recombination centers for electron and holes, playing a critical role in the trapping process: an excess of oxygen vacancies will result in more photogenerated electrons being trapped thus decreasing their contribution to the photoelectrochemical processes $[37,56,57]$. 
The recombination probability is also affected by the flat-band potential, $\phi_{F B}$, which is the potential that needs to be applied to the semiconductor to reduce the band bending to zero, that is, at this potential there is no depleted space charge layer. The $\phi_{F B}$ value is related to the potential drop at the depletion space charge layer, $\phi_{S C}$, and the applied external potential, $\phi_{A}$, according to:

$$
\phi_{S C}=\phi_{A}-\phi_{F B}
$$

Assuming a constant value of $\phi_{A}$, the higher and more negative the value of $\phi_{F B}$, the higher the value of $\phi_{S C}$ and, consequently, the stronger the electrical field within the depleted space charge layer, which is the driving force to separate the photogenerated electron-hole pairs. Therefore, to reduce the recombination probability $\phi_{F B}$ should be high and negative $[16,37]$.

Values of $\phi_{F B}$ can be determined from the intercept of the straight line in M-S plots with the potential axis. These values for the compact $\mathrm{TiO}_{2}$ film and for the different nanostructures are also shown in Table 2. It can be observed that $\phi_{F B}$ is more negative for the compact $\mathrm{TiO}_{2}$ film, which indicates that the recombination probability is lower than for the $\mathrm{TiO}_{2}$ nanostructures. However, the low values of $N_{D}$ in the compact film reduce considerably its photoelectrochemical performance, as it will be demonstrated later. On the other hand, $\phi_{F B}$ becomes more negative with increasing $\mathrm{Re}$, that is, nanosponges formed under hydrodynamic conditions possess more negative values of $\phi_{F B}$ than nanotubes formed under stagnant conditions. This negative shift of $\phi_{F B}$ leads to a displacement of the Fermi level towards the conduction band edge and, consequently, to a larger band bending and electrical field within the depleted space charge layer [22, 
26, 37]. Therefore, from the point of view of the charge recombination probability, these results indicate that this probability is lower in the case of the nanosponges.

\subsection{Photoelectrochemical water splitting measurements}

Figure 7 shows the photoelectrochemical water splitting performance under simulated sunlight AM 1.5 conditions for the different nanostructures. It can be observed in terms of the photocurrent transient vs. potential curves, that the nanostructures obtained under hydrodynamic conditions, present a higher performance in comparison with the nanotubes (anodized at the same potential, time and electrolyte as the nanosponges but at $\operatorname{Re}=0)$ and a significantly higher photoelectrochemical behavior with respect to the compact $\mathrm{TiO}_{2}$ layer. The high photocurrent density of the nanosponges, especially when Re increases, is directly related to their superior electrical conductivity [14]. These results are in well agreement with the EIS (resistance values) and MS measurements ( $N_{D}$ and $\phi_{F B}$ values). It is known that a large population of surface-active sites due to the increase in thickness in the nanosponges will lead to the enhanced rate of the photoelectrochemical reaction over the photoelectrode $[28,58]$. In order to know if the photocurrent increase was due to the higher thickness of the nanosponges or due to its intrinsic morphology which could proporcionate a high surface area, photocurrent transient vs potential curves were performed for thicker nanotubes $(\sim 4 \mu \mathrm{m}$, anodized at $55 \mathrm{~V}$ in ethylenglycol based electrolytes with 2 wt. \% of water and $0.1 \mathrm{M}$ of NH4F and annealed at $450{ }^{\circ} \mathrm{C}$ ). Figure 8 shows that the photocurrents obtained for the nanotubes are lower than for the thicker nanosponges (obtained at $\mathrm{Re}=400$ ). In fact, the photocurrent obtained for the nanotube morphology is lower than the obtained for the 
rest of thinner nanosponges. This confirms the suitability of the nanosponge morphology for photocatalysis purposes.

Furthermore, the maximum and minimum for light on and light off shown in Figure 7 describe two competitive processes, i.e., the former related to the generation of electronhole pairs at the semiconductor/electrolyte interface and the latter to the recombination of theses pairs $[2,4,16,59,60]$. Figure 7 shows that the initial anodic peak (maximum) is present for all the nanosponges and nanotubes. On the other hand, when the light is switched off, a cathodic peak is observed only for the nanotubes and for the nanosponges synthesised at the lowest $\operatorname{Re}(\operatorname{Re}=100)$, due to the recombination of the conduction band electrons with the holes trapped at the surface, consequently decreasing their photocurrent response.

It is remarkable that for both nanotubes and nanosponges, the photocurrent under illumination increases with the applied potential until a potential value of $-0.2 \mathrm{~V}$ whereas for the compact layer photocurrents remains almost constant from the beginning of the tests. On the other hand, a dark current remains very low in all the studied samples.

Additionally, it is important to highlight that the nanosponges obtained under hydrodynamic conditions do not deteriorate with time. Figure 9 shows as an example, the photostability in $1 \mathrm{M} \mathrm{KOH}$ solution during 1 hour of the different nanostructures holding at $500 \mathrm{mV}$ the potential under AM 1.5 illumination. From Figure 9 it can be clearly observed that nanosponges synthesized at higher Reynolds numbers are stable with time. 


\section{CONCLUSIONS}

The use of controlled hydrodynamic conditions during titanium anodization generates a $\mathrm{TiO}_{2}$ interlinked with high surface area morphology (nanosponge morphology).

An increase in $N_{D}$ has been observed for the $\mathrm{TiO}_{2}$ nanostructures (nanotubes and nanosponges) compared with the compact $\mathrm{TiO}_{2}$ layer, which improves the $n$-type character of the nanostructures and enhances electron transport. On the other hand, $N_{D}$ is lower for the nanosponges than for the nanotubes, which results in thicker depleted layers in the case of the nanosponges that provide a strong electric field essential for a successful separation of photogenerated electrons and holes.

The displacement of the $\phi_{F B}$ towards more negative values in the case of the nanosponges (with increasing Re) results in an up-shift of Fermi level towards the conduction band and a somewhat larger band bending, which facilitate electron-hole separation.

$\mathrm{TiO}_{2}$ nanosponges enhance the photoelectrochemical activity for water splitting compared with nanotubes and compact $\mathrm{TiO}_{2}$ layers, in particular those anodized at higher Reynolds numbers, as a consequence of higher surface areas and a better charge separation.

$\mathrm{TiO} 2$ nanosponges synthesized at high Reynolds numbers have been demonstrated to be stable with time. 
Acknowledgements: Authors would like to express their gratitude for their financial support to the Generalitat Valenciana (PROMETEOII/2014/009), to Fundación Iberdrola and to the Universitat Politècnica de València.

\section{REFERENCES}

[1] J. M. Macak, H. Tsuchiya, A. Ghicov, K. Yasuda, R. Hahn, S. Bauer, P. Schmuki, Curr. Opin. Solid St. Mater. Sci. 11 (2007) 3-18.

[2] A. Hagfeldt, H. Lindström, S. Södergren, S. E. Lindquist, J. Electroanal. Chem. 381 (1995) 39-46.

[3] T. Bak, J. Nowotny, M. Rekas, C. C. Sorrell, Int. J. Hydrogen Energ. 27 (2002) 19-26.

[4] M. Radecka, M. Wierzbicka, S. Komornicki, M. Rekas, Physica B: Condensed Matter 348 (2004) 160-168.

[5] W. H. Leng, Z. Zhang, J. Q. Zhang, C. N. Cao, J. Phys. Chem. B 109 (2005) 15008-15023.

[6] P. Pillai, K. S. Raja, M. Misra, J. Power Sources 161 (2006) 524-530.

[7] A. G. Muñoz, Electrochim. Acta 52 (2007) 4167-4176.

[8] A. G. Muñoz, Q. Chen, P. Schmuki, J. Solid State Electrochem. 11 (2007) 1077-1084.

[9] H. Tsuchiya, J. M. Macak, A. Ghicov, A. S. Räder, L. Taveira, P. Schmuki, Corros. Sci. 49 (2007) 203-210.

[10] S. P. Albu, A. Ghicov, J. M. Macak, R. Hahn, P. Schmuki, Nano Lett. 7 (2007) 1286-1289.

[11] M. Ni, M. K. H. Leung, D. Y. C. Leung, K. Sumathy, Renew. Sust. Energ. Rev. 11 (2007) 401-425.

[12] M. Hepel, I. D. Kumarihamy, Int. J. Hydrogen Energ. 32 (2007) 2693-2702.

[13] S. K. Mohapatra, M. Misra, V. K. Mahajan, K. S. Raja, J. Catal. 246 (2007) 362-369.

[14] P. Xiao, D. Liu, B. Batalla Garcia, S. Sepehri, Y. Zhang, G. Cao, Sensor Actuat. B-Chem. 134 (2008) 367-372. 
[15] F. Fabregat-Santiago, E. M. Barea, J. Bisquert, G. K. Mor, K. Shankar, C. A. Grimes, J. Am. Chem. Soc. 130 (2008) 11312-11316.

[16] M. Radecka, M. Rekas, A. Trenczek-Zajac, K. Zakrzewska, J. Power Sources 181 (2008) 46-55.

[17] Z. Liu, B. Pesic, K. S. Raja, R. R. Rangaraju, M. Misra, Int. J. Hydrogen Energ. 34 (2009) 3250-3257.

[18] D. Wang, Y. Liu, B. Yu, F. Zhou, W. Liu, Chem. Mater. 21 (2009) 1198-1206.

[19] T. S. Kang, A. P. Smith, B. E. Taylor, M. F. Durstock, Nano Lett. 9 (2009) 601-606.

[20] A. Wolcott, W. A. Smith, T. R. Kuykendall, Y. Zhao, J. Z. Zhang, Small 5 (2009) 104-111.

[21] M. M. Pedemonte, A. Visintin, A. L. Capparelli, Int. J. Hydrogen Energ. 35 (2010) 6069-6073.

[22] S. Palmas, A. M. Polcaro, J. R. Ruiz, A. Da Pozzo, M. Mascia, A. Vacca, Int. J. Hydrogen Energ. 35 (2010) 6561-6570.

[23] P. Pu, H. Cachet, E. M. M. Sutter, Electrochim. Acta 55 (2010) 5938-5946.

[24] D. D’Elia, C. Beauger, J. F. Hochepied, A. Rigacci, M. H. Berger, N. Keller, V. Keller-Spitzer, Y. Suzuki, J. C. Valmalette, M. Benabdesselam, P. Achard, Int. J. Hydrogen Energ. 36 (2011) 14360-14373.

[25] S. Palmas, A. Da Pozzo, M. Mascia, A. Vacca, A. Ardu, R. Matarrese, I. Nova, Int. J. Hydrogen Energ. 36 (2011) 8894-8901.

[26] G. Wang, H. Wang, Y. Ling, Y. Tang, X. Yang, R. C. Fitzmorris, C. Wang, J. Z. Zhang, Y. Li, Nano Lett. 11 (2011) 3026-3033.

[27] D. P. Oyarzún, R. Córdova, O. E. Linarez Pérez, E. Muñoz, R. Henríquez, M. López Teijelo, H. Gómez, J. Solid State Electrochem. 15 (2011) 2265-2275.

[28] L. x. Sang, Z. Zhi-yu, B. Guang-mei, D. Chun-xu, M. Chong-fang, Int. J. Hydrogen Energ. 37 (2012) 854-859.

[29] S. A. A. Yahia, L. Hamadou, A. Kadri, N. Benbrahim, E. M. M. Sutter, J. Electrochem. Soc. 159 (2012) K83-K92.

[30] L. Yu, Z. Wang, L. Shi, S. Yuan, Y. Zhao, J. Fang, W. Deng, Appl. Catal. BEnviron. 113-114 (2012) 318-325.

[31] R. Sánchez-Tovar, K. Lee, J. García-Antón, P. Schmuki, Electrochem. Commun. 26 (2013) 1-4.

[32] L. Sun, J. Cai, Q. Wu, P. Huang, Y. Su, C. Lin, Electrochim. Acta 108 (2013) 525-531. 
[33] P. Acevedo-Peña, I. González, J. Electrochem. Soc. 160 (2013) H452-H458.

[34] L.-K. Tsui, T. Homma, G. Zangari, J. Phys. Chem. C 117 (2013) 6979-6989.

[35] L.-K. Tsui, G. Zangari, Electrochim. Acta 121 (2014) 203-209.

[36] R. G. Freitas, M. A. Santanna, E. C. Pereira, J. Power Sources 251 (2014) 178186.

[37] D. Wang, X. Zhang, P. Sun, S. Lu, L. Wang, C. Wang, Y. Liu, Electrochim. Acta 130 (2014) 290-295.

[38] L. Aïnouche, L. Hamadou, A. Kadri, N. Benbrahim, D. Bradai, Electrochim. Acta 133 (2014) 597-609.

[39] N. S. Cheng, Ind. Eng. Chem. Res. 47 (2008) 3285-3288.

[40] S. T. Nishanthi, S. Iyyapushpam, B. Sundarakannan, E. Subramanian, D. Pathinettam Padiyan, Sep. Purif. Technol. 131 (2014) 102-107.

[41] X. Zhou, T. Shi, J. Wu, H. Zhou, Appl. Surf. Sci. 287 (2013) 359-368.

[42] R. M. Fernández-Domene, E. Blasco-Tamarit, D. M. García-García, J. GarcíaAntón, J. Electrochem. Soc. 161 (2014) C25-C35.

[43] V. A. Alves, R. Q. Reis, I. C. B. Santos, D. G. Souza, T. d. F. Gonçalves, M. A. Pereira-da-Silva, A. Rossi, L. A. da Silva, Corros. Sci. 51 (2009) 24732482.

[44] G. J. Brug, A. L. G. van den Eeden, M. Sluyters-Rehbach, J. H. Sluyters, J. Electroanal. Chem. 176 (1984) 275-295.

[45] B. Hirschorn, M.E. Orazem, B. Tribollet, V. Vivier, I. Frateur, M. Musiani, Electrochim. Acta 55 (2010) 6218-6227.

[46] X. Lu, G. Wang, T. Zhai, M. Yu, J. Gan, Y. Tong, Y. L, Nano Lett. 12 (2012) 1690-1696.

[47] Z. Jiang, X. Dai, H. Middleton, Mater. Chem. Phys. 126 (2011) 859-865.

[48] D. S. Kong, W. H. Lu, Y. Y. Feng, Z. Y. Yu, J. X. Wu, W. J. Fan, H. Y. Liu, J. Electrochem. Soc. 156 (2009) C39-C44.

[49] D. Sazou, K. Saltidou, M. Pagitsas, Electrochim. Acta 76 (2012) 48-61.

[50] B. Roh, D. D. Macdonald, Russ. J. Electrochem. 43 (2007) 125-135.

[51] H. Peng, Phys. Lett. A 372 (2008) 1527-1530.

[52] G. Wang, H. Wang, Y. Ling, Y. Tang, X. Yang, R. C. Fitzmorris, C. Wang, J. Z. Zhang, Y. Li, Nano Lett. 11 (2011) 3026-3033. 
[53] A. M. Schmidt, D. S. Azambuja, E. M. A. Martini, Corros. Sci. 48 (2006) 2901-2912.

[54] O. Carp, C. L. Huisman, A. Reller, Prog. Solid State Chem. 32 (2004) 33-177.

[55] U. König, J. W. Schultze, Solid State Ionics 53-56, Part 1 (1992) 255-264.

[56] B. J. Morgan, G. W. Watson, Phys. Rev. B 80 (2009) 233102.

[57] H. Irie, Y. Watanabe, K. Hashimoto, J. Phys. Chem. B 107 (2003) 5483-5486.

[58] J. Gan, X. Lu, T. Zhai, Y. Zhao, S. Xie, Y. Mao, Y. Zhang, Y. Yang, Y. Tong, J. Mater. Chem. 21 (2011) 14685-14692.

[59] D. Tafalla, P. Salvador, R. M. Benito, J. Electrochem. Soc. 137 (1990) 18101815 .

[60] N. W. Duffy, L. M. Peter, R. M. G. Rajapakse, K. G. U. Wijayantha, Electrochem. Commun. 2 (2000) 658-662.

\section{$\underline{\text { Tables captions }}$}

Table 1. Equivalent circuit parameters for $\mathrm{TiO}_{2}$ compact layer and $\mathrm{TiO}_{2}$ nanostructures (nanotubes and nanosponges) at different values of Re.

Table 2. Values of $N_{D}$ and $\phi_{F B}$ for $\mathrm{TiO}_{2}$ compact layer and $\mathrm{TiO}_{2}$ nanostructures (nanotubes and nanosponges) at different values of Re.

\section{Figures captions}

Figure 1. SEM images of the $\mathrm{TiO}_{2}$ nanostructures (a) under stagnant conditions $(\mathrm{Re}=$ $0)$ and (b) under hydrodynamic conditions $(\operatorname{Re}>0)$.

Figure 2. Length of the nanotubes $(\operatorname{Re}=0)$ and nanosponges $(\operatorname{Re}>0)$ as a function of Re. 
Figure 3. Raman spectra of as-prepared and annealed $\mathrm{TiO}_{2}$ nanostructures for $\mathrm{Re}=0$ and $\operatorname{Re}=300$.

Figure 4. Experimental Nyquist (a, b), Bode-phase (c) and Bode-module (d) plots for the compact $\mathrm{TiO}_{2}$ film and $\mathrm{TiO}_{2}$ nanostructures formed at different $\mathrm{Re}$ values.

Figure 5. Electrical equivalent circuit used to simulate experimental EIS data.

Figure 6. (a) Mott-Schottky plots obtained at a frequency of $10 \mathrm{kHz}$ for the compact $\mathrm{TiO}_{2}$ film and $\mathrm{TiO}_{2}$ nanostructures formed at different Re values; (b) magnification of Figure 6(a) showing only the M-S plots for the $\mathrm{TiO}_{2}$ nanostructures.

Figure 7. Photocurrent transient vs. potential curves for the compact $\mathrm{TiO}_{2}$ film and $\mathrm{TiO}_{2}$ nanostructures formed at different $\mathrm{Re}$ values under simulated sunlight AM 1.5 illumination.

Figure 8. Photocurrent transient vs. potential curves for $\sim 4 \mu \mathrm{m}$ nanotubes and $\sim 3.5 \mu \mathrm{m}$ nanosponges under AM 1.5 illumination.

Figure 9. Photostability experiments carried out in a $1 \mathrm{M} \mathrm{KOH}$ solution at $500 \mathrm{mV}$ under AM 1.5 illumination. 


\begin{tabular}{|c|c|c|c|c|c|c|c|c|}
\hline$R e$ & $R_{S} / \Omega \mathrm{cm}^{2}$ & $C_{1} / \mu \mathrm{F} \mathrm{cm} \mathrm{cm}^{-2}$ & $\alpha_{1}$ & $R_{l} / \mathrm{k} \Omega \mathrm{cm}^{2}$ & $C_{2} / \mu \mathrm{F} \mathrm{cm} \mathrm{cm}^{-2}$ & $\alpha_{2}$ & $R_{2} / \mathrm{k} \Omega \mathrm{cm}^{2}$ & $\chi^{2}\left(\times 10^{-3}\right)$ \\
\hline 0 & $41 \pm 4$ & $69 \pm 12$ & $0.84 \pm 0.05$ & $8.9 \pm 2.6$ & $365 \pm 63$ & $0.95 \pm 0.09$ & $576 \pm 42$ & 5 \\
\hline 100 & $36 \pm 6$ & $71 \pm 10$ & $0.65 \pm 0.03$ & $3.6 \pm 1.2$ & $434 \pm 101$ & $0.98 \pm 0.04$ & $289 \pm 27$ & 4 \\
\hline 200 & $43 \pm 6$ & $40 \pm 8$ & $0.68 \pm 0.02$ & $2.8 \pm 0.5$ & $505 \pm 112$ & $0.99 \pm 0.01$ & $454 \pm 55$ & 2 \\
\hline 300 & $31 \pm 7$ & $33 \pm 5$ & $0.68 \pm 0.07$ & $2.4 \pm 0.2$ & $477 \pm 116$ & $0.97 \pm 0.07$ & $432 \pm 104$ & 8 \\
\hline 400 & $31 \pm 3$ & $10 \pm 2$ & $0.70 \pm 0.03$ & $2.1 \pm 0.4$ & $902 \pm 208$ & $0.89 \pm 0.06$ & $860 \pm 282$ & 9 \\
\hline COMPACT & $39 \pm 6$ & $3 \pm 1$ & $0.71 \pm 0.02$ & $201 \pm 23$ & $29 \pm 6$ & $0.96 \pm 0.04$ & $255 \pm 43$ & 0.3 \\
\hline
\end{tabular}


Table 2

\begin{tabular}{|c|c|c|}
\hline $\boldsymbol{R e}$ & $\boldsymbol{N}_{\boldsymbol{D}}\left(\times \mathbf{1 0}^{\mathbf{1 9}} \mathbf{c m}^{-\mathbf{3}}\right)$ & $\left.\phi_{\boldsymbol{F} \boldsymbol{B}} / \mathbf{V ~ v s} \mathbf{( A g} / \mathbf{A g C l}\right)$ \\
\hline 0 & $3.6 \pm 0.6$ & $-0.15 \pm 0.07$ \\
\hline 100 & $1.4 \pm 0.3$ & $-0.17 \pm 0.04$ \\
\hline 200 & $1.1 \pm 0.1$ & $-0.17 \pm 0.02$ \\
\hline 300 & $1.1 \pm 0.2$ & $-0.21 \pm 0.01$ \\
\hline 400 & $0.9 \pm 0.1$ & $-0.33 \pm 0.03$ \\
\hline & & \\
\hline COMPACT & $0.17 \pm 0.01$ & $-0.55 \pm 0.01$ \\
\hline
\end{tabular}


Figure 1

Click here to download Figure(s): Figure 1.doc

a) $\operatorname{Re}=0$

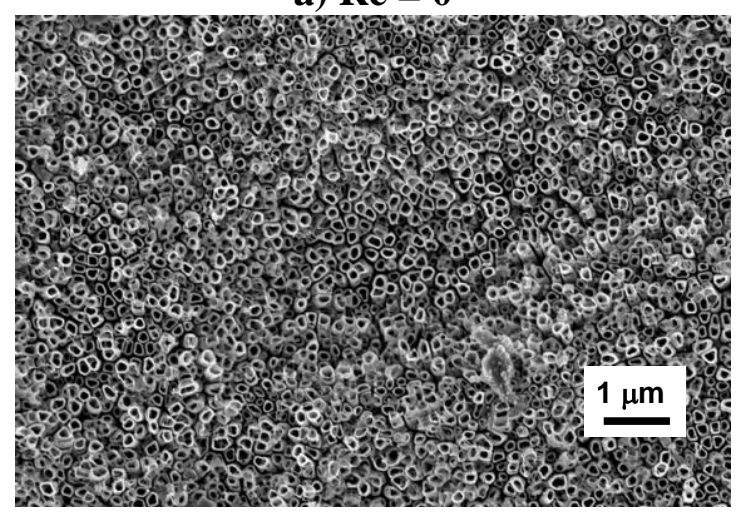

b) $\mathrm{Re}=\mathbf{3 0 0}$

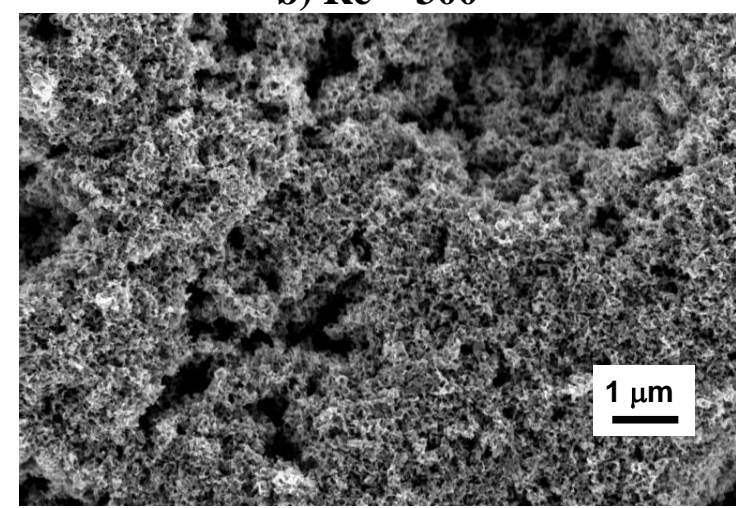


Figure 2

Click here to download Figure(s): Figure 2.doc

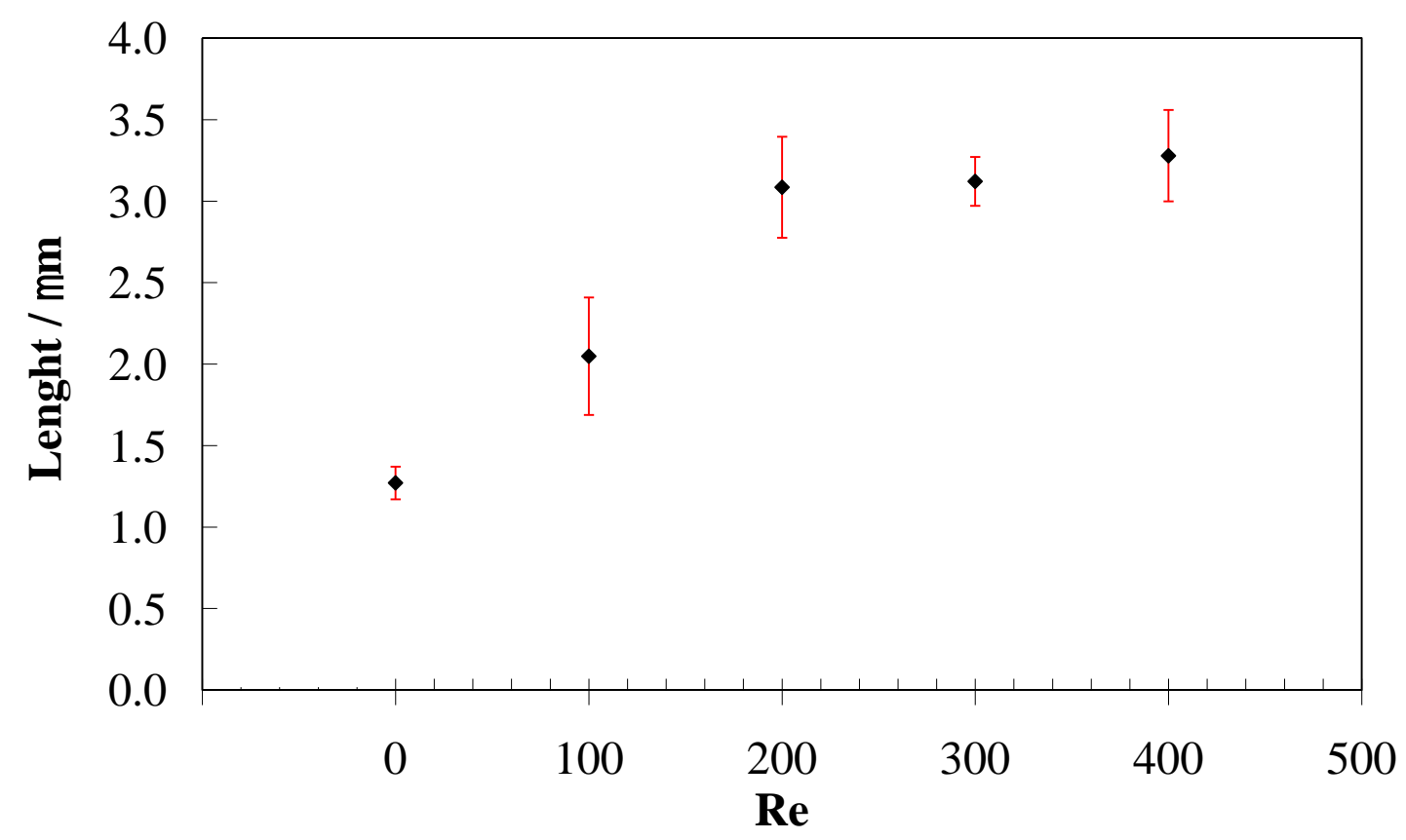


Click here to download Figure(s): Figure 3.doc

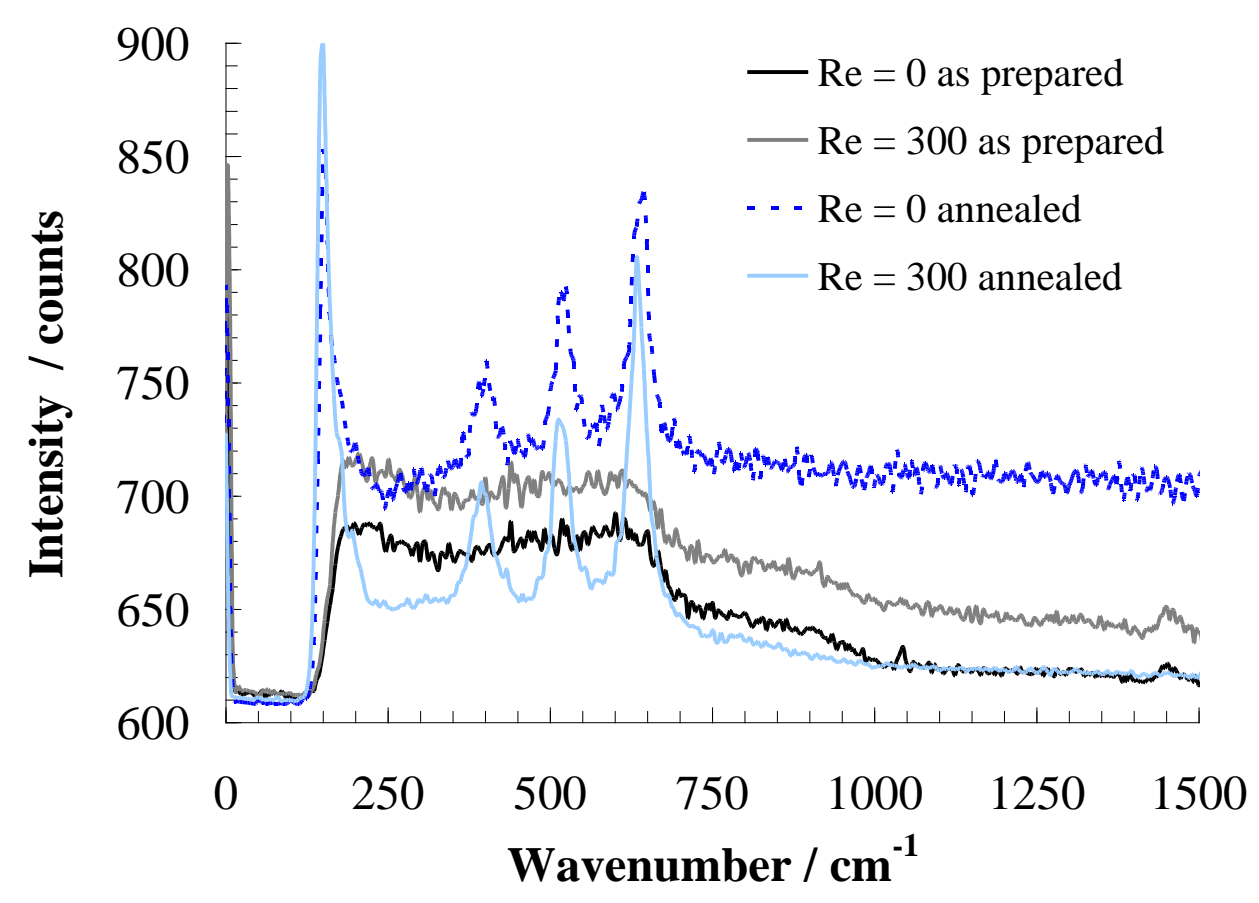



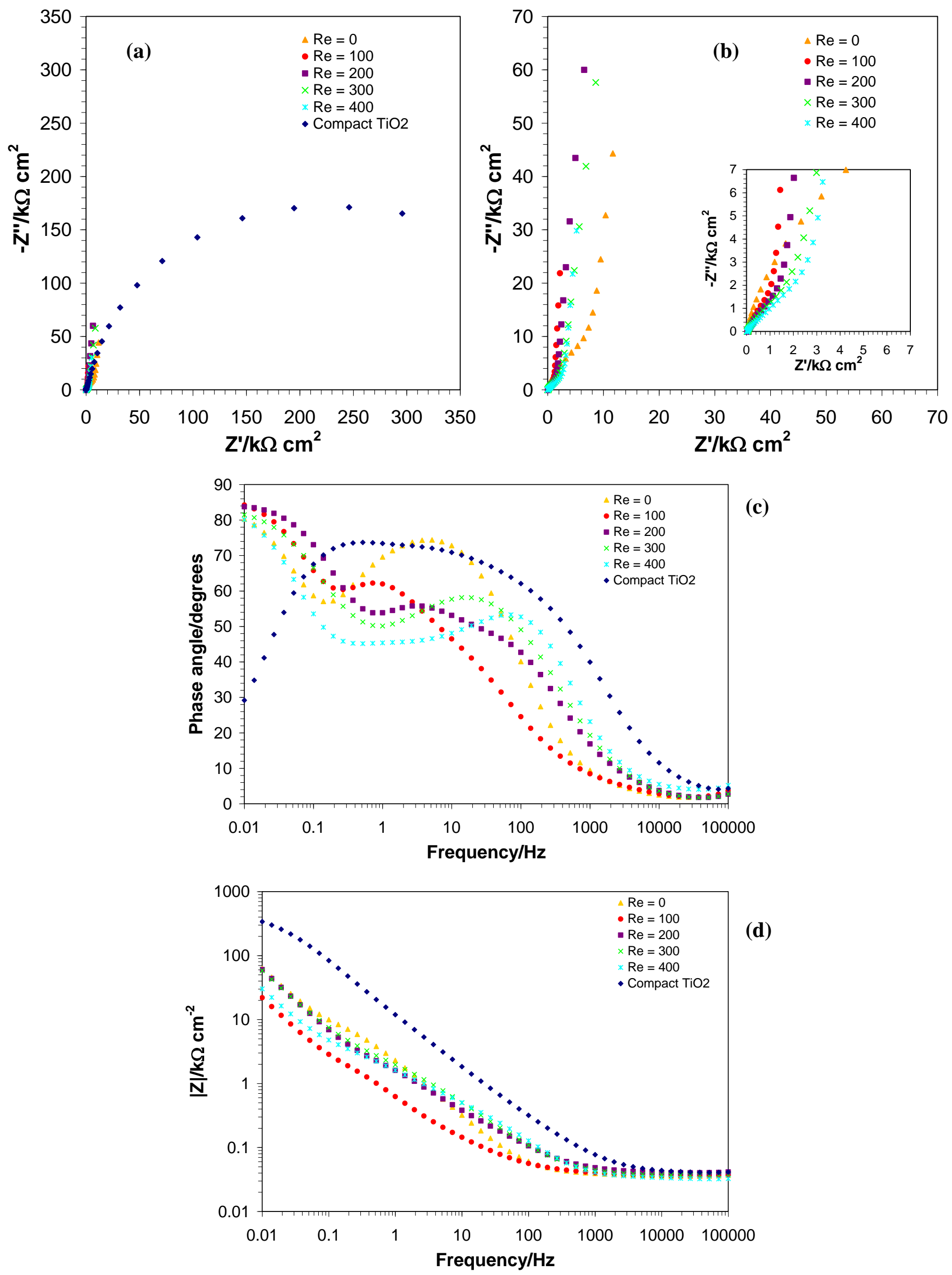
Click here to download Figure(s): Figure 5.doc

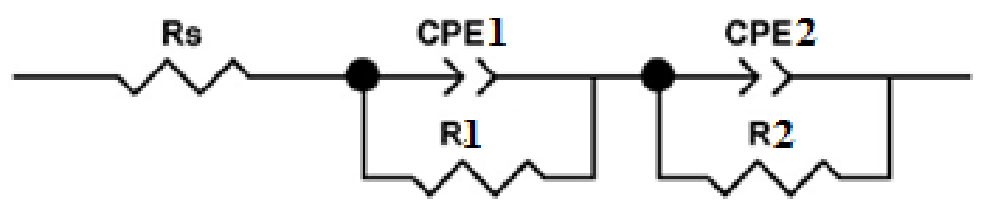

Figure 5

$\stackrel{\text { PI }}{\longrightarrow}$ 
Figure 6

Click here to download Figure(s): Figure 6.doc

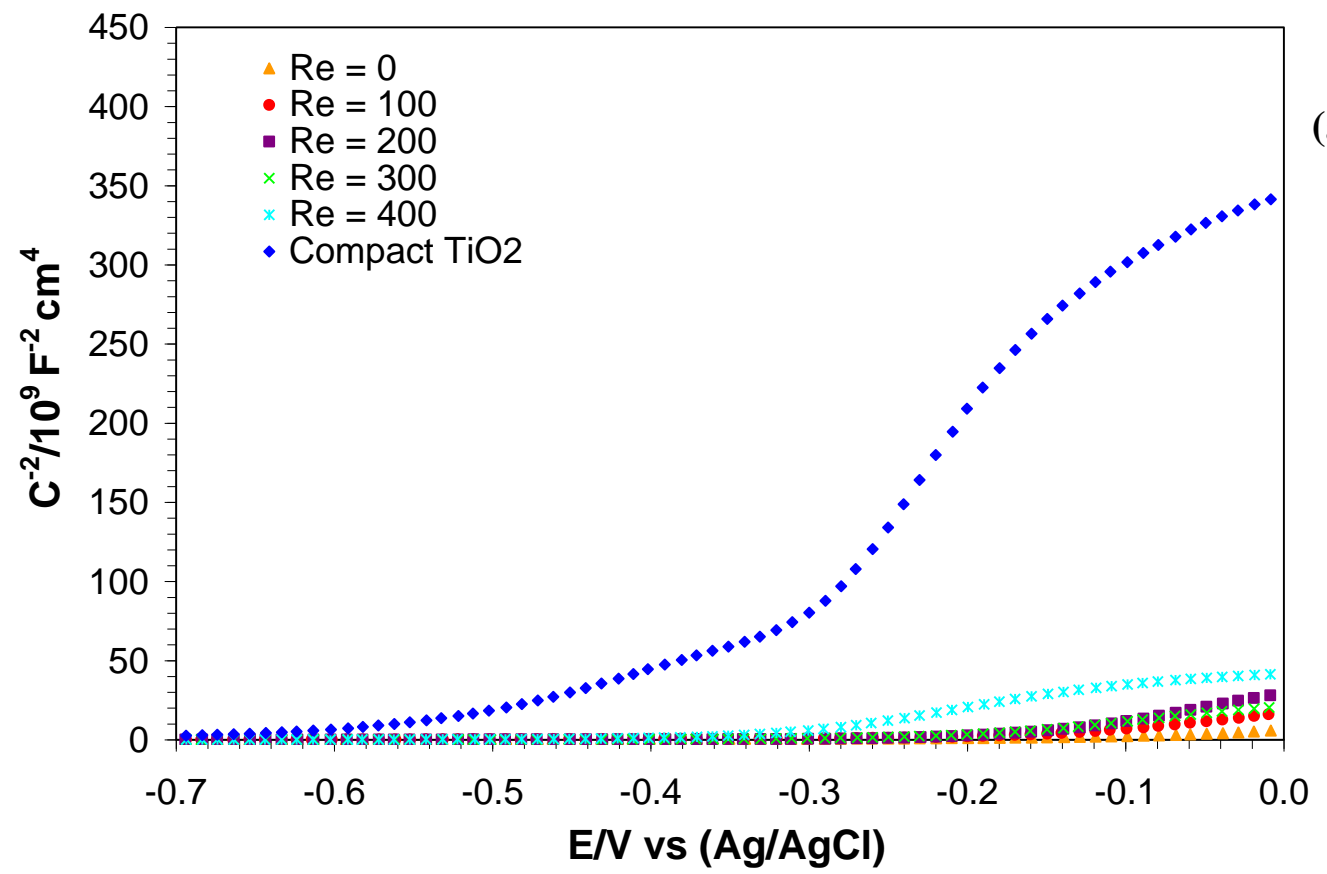

(a)

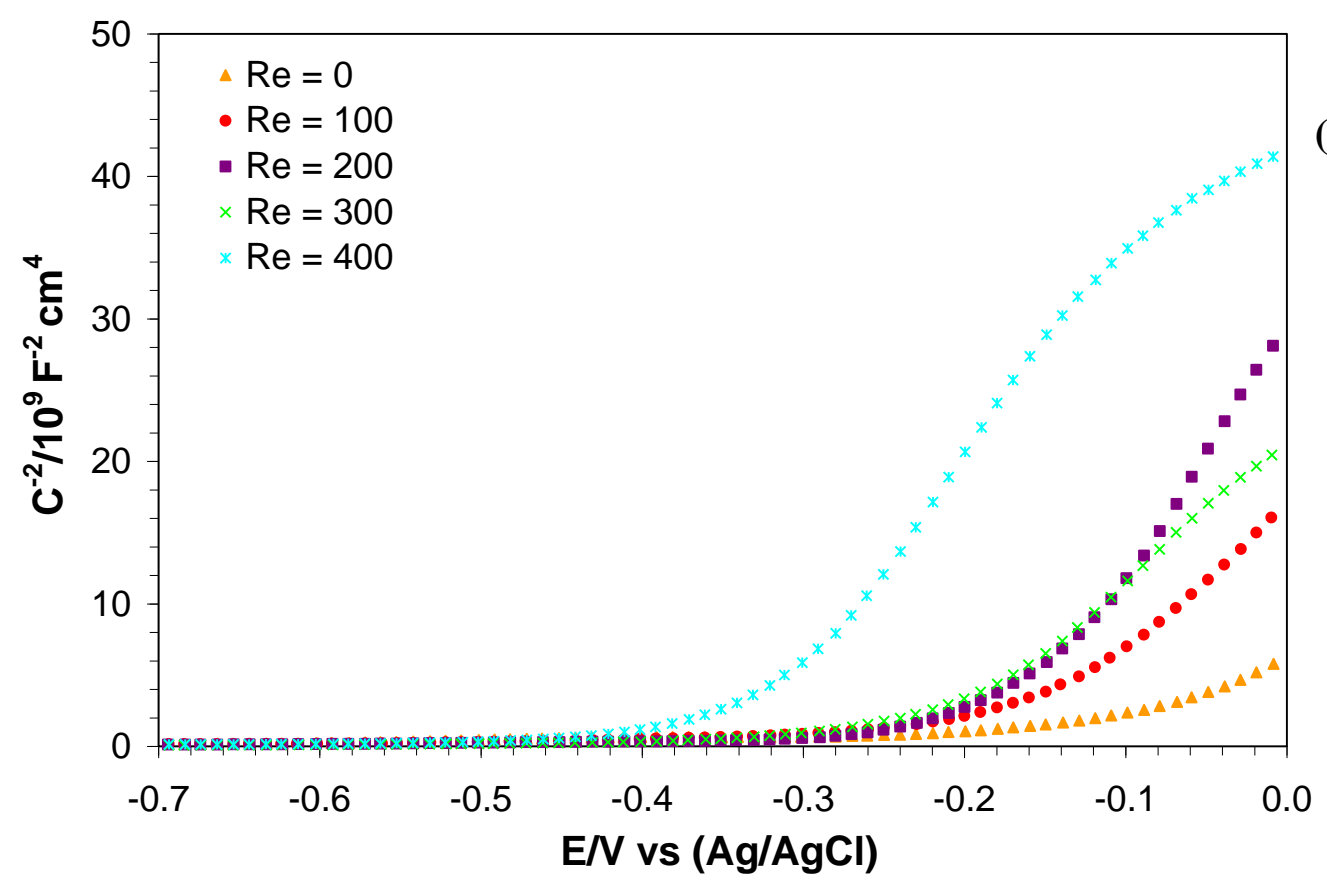

(b) 
Figure 7

Click here to download Figure(s): Figure 7.doc

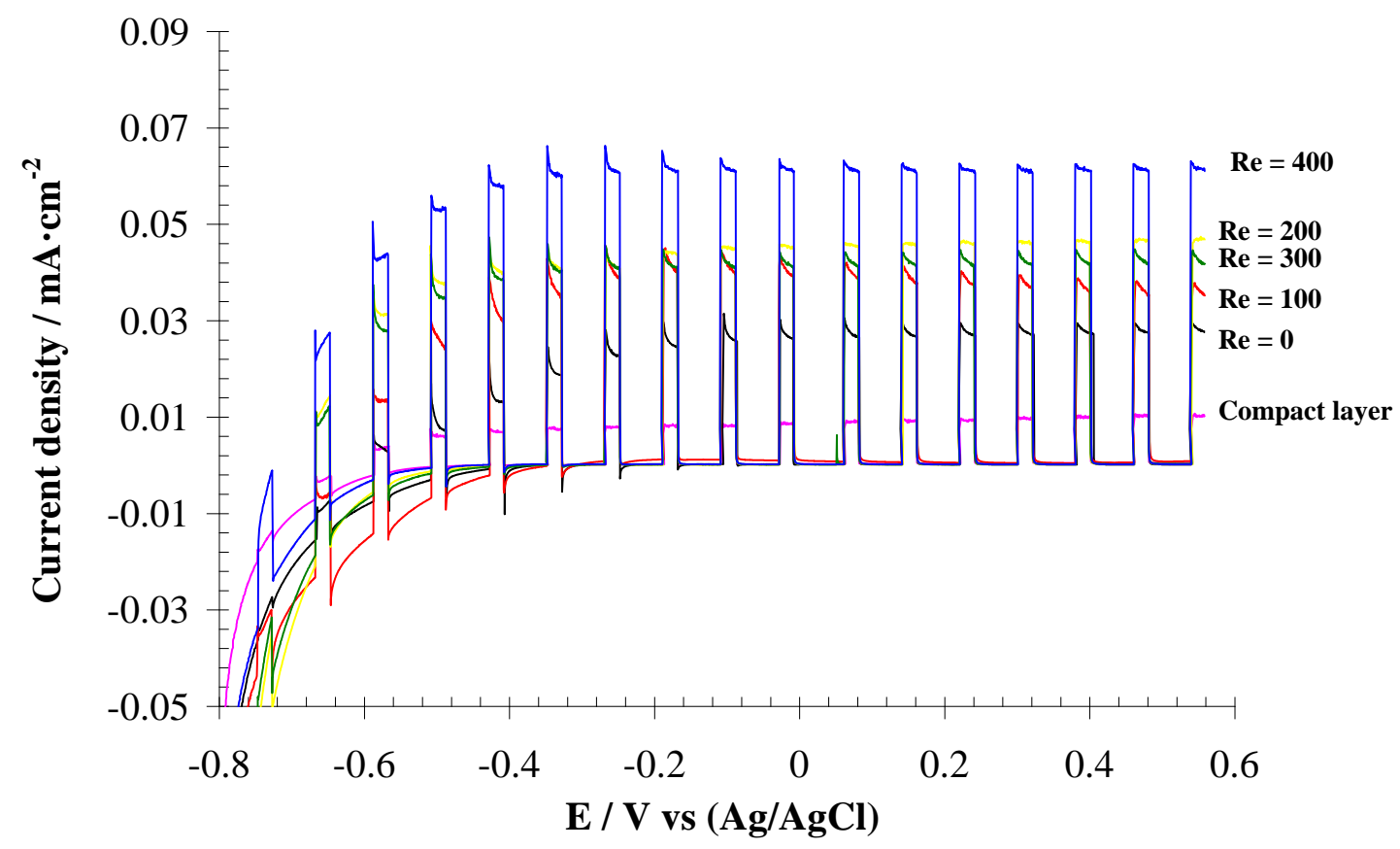


Figure 8

Click here to download Figure(s): Figure 8.doc

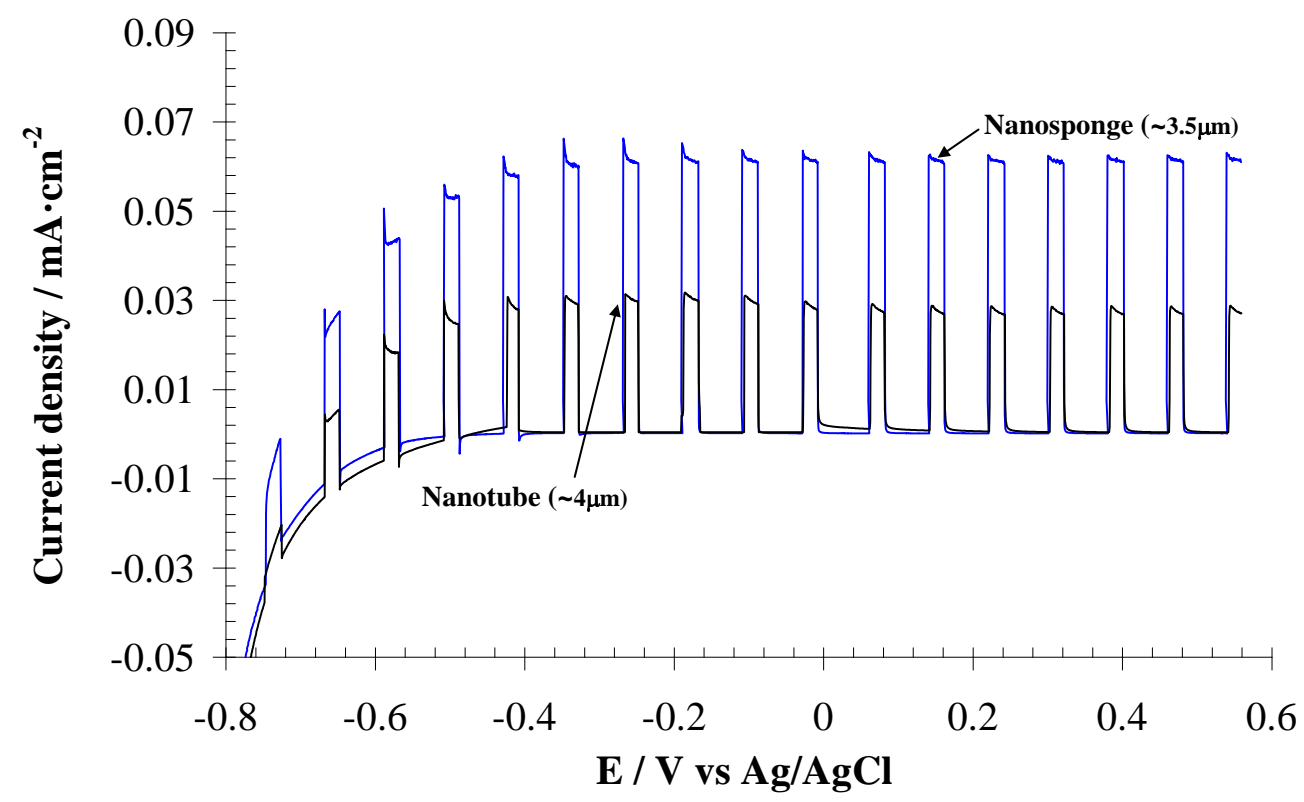


Figure 9

Click here to download Figure(s): Figure 9.doc

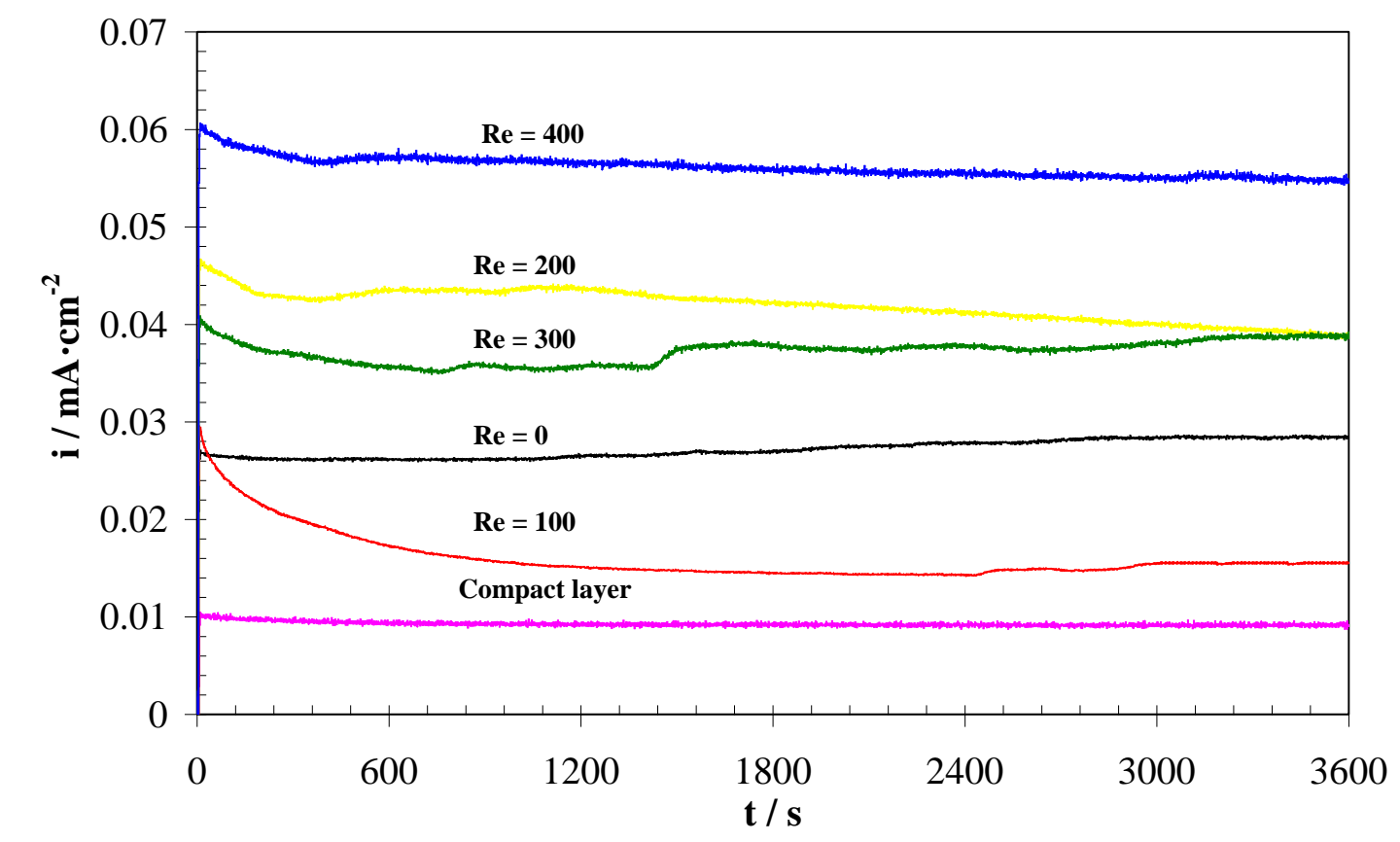

